\title{
Efficacy of modified two point fixation versus three point fixation in management of moderate energy orbitozygomatic complex fractures (Clinical and radiographic study)
}

\author{
Original \\ Abdel Aziz Baiomy Abdullah Baiomy ${ }^{a}$, Abdelbadia A. Abdelmabood and Mohamed $^{b}$ \\ Article \\ Fouad Abdallah Edrees ${ }^{c}$ \\ Department of Oral and Maxillofacial Surgery, Faculty of Dentistry, ${ }^{a}$ Al-Azhar \\ University, Assiut (Boys), ${ }^{b}$ Al-Zagazig University, 'Department of Oral Medicine, \\ Periodontology, Oral Diagnosis and Dental Radiology, Faculty of Dentistry, Al- \\ Azhar University, Assiut (Boys), Egypt
}

\begin{abstract}
Background: Orbitozygomatic complex (OZC) fractures are second most common fracture among facial skeletal injuries. It has been reported that three point fixation is the most acceptable technique for management of moderate energy OZC fractures. However, it has several drawbacks such as skin scare and palpable hardware over lateral orbital rim.

Aim: The purpose of current study was to compare modified two point (the ZM buttress and infraorbital rim) and three point method of internal fixation in moderate energy OZC fractures.

Patients and Methods: This randomized controlled trial was conducted on of 32 patients with unilateral moderate energy OZC fractures of both genders. They were divided into equal two groups (group I, three point fixation and group II, modified two point fixation). Patient demographics and both clinical and CT radiographical assessments were done postoperatively after 6 months to evaluate postoperative complications, patient satisfaction score , and quality of bone reduction.

Results: Clinically There was highly statistical significant difference between groups in aspects of mean operation time, numbers of postoperative complications and values of patient satisfaction score ( $p$ value $=0.015,0.003,0.0016$ respectively). Postoperative radiographic measurements and means of difference between affected and unaffected sides revealed nonsignificant difference between groups $(p>0.05)$.

Conclusio: Modified two point fixation technique is effective alternative to three point fixation technique in management of moderate energy OZC fractures with advantages of reduced operation time, fewer complications, higher patient satisfaction score.
\end{abstract}

Key Words: Multi-detector computed tomography, OZC fracture, Orbital fracture, Rigid internal fixation, Three point fixation, Two point fixation.

Received: 21 July 2020, Accepted: 20 December 2020.

Corresponding Author: Abdel Aziz Baiomy Abdullah Baiomy, Department of Oral and Maxillofacial Surgery, Faculty of Dentistry, Al-Azhar University, Assiut, Egypt, Tel.: +20552240879, Mobile: +201004227819, E-mail: abdelazizbaiomy@azhar.edu.eg.

ISSN: 2090-097X, April 2020, Vol. 11, No. 2

\section{INTRODUCTION}

Orbitozygomatic complex fracture (OZC) is one of the most commonly encountered injuries of craniofacial skeleton. It rank third in incidence among all bone injuries occurring in humans and $60 \%$ of all facial fractures ${ }^{[1-4]}$.

OZC fractures could lead to multiple ocular affections, such as diplopia, enophthalmos, or restricted eye movement, because of significant increase in orbital volume after the displacement of zygomatico-maxillary complex laterally along the vertical axis ${ }^{[5-7]}$. Moreover, orbital floor fracture as a one of component of the OZC fracture is significantly occur in $75 \%$ of OZC cases $^{[5-8]}$.
The zygomatic bone play significant role in the formation of the floor and lateral wall of orbit, thus it acts as one of the most common contributors to the orbital integrity ${ }^{[3,9]}$. Accordingly, eye movements depends on the correct three dimensional positioning of the bones that make up the orbit. Because of this complex three dimensional geometric architecture of the orbit, restoration of normal orbital volume in OZC fractures becomes a big challenge to maxillofacial sur-geons, especially in cases burdened with orbital wall/s defects ${ }^{[10]}$.

The main objective for the management of OZC fractures is exploration and release of herniated/entrapped 
soft tissue and restoration of the original orbital volume and facial configu-ration ${ }^{[11]}$. Restoring of the orbital volume may be conducted through accurate reduction of dis-placed bones combined with the use of implants for reconstruction and stabilization of the orbital walls ${ }^{[11-13]}$.

The standard treatment for OZC fracture accompanied by orbital floor fracture is open reduction and internal fixation alone or in combination with reconstruction orbital floor ${ }^{[14,15]}$ and number of fixation sites are selected based on stability of the fractured zygoma ${ }^{[16,17]}$. Among fixation sites, zygomaticofrontal (ZF) suture followed by zygomaticosphenoidal (ZS) suture has been a key site for anatomical alignment and secure fixation. Therefore, these sites have been the primary location of fixation ${ }^{[18,19]}$.

Several studies $\left.{ }^{[20}-23\right]$ concluded that the three point fixation (ZF suture, inferior orbital rim and zygomaticomaxillary ( $\mathrm{ZM})$ buttress) technique is superior to two point fixation (ZF suture and zygomaticomaxillary buttress) technique for three dimensional reposition of the bone in displaced zygomatic complex fracture to restore original orbital volume and avoid enophthalmos. In the opposite side, several researchers recommend two point fixation over three point fixation as they found that three point fixation did not achieve any extra benefits regarding reduction and stabilization aspect, although presence of more hardware. Moreover this technique increase sur-gery time ,and may result in noticeable scars ${ }^{[24-26]}$. However, the internal fixation at ZF suture that is primary point of fixation in both techniques may cause also noticeable scars through lateral eyebrow region above ZF suture, uncomfortable palpability of plates on thin skin, ectropion, and risk of drill penetration into the anterior cranial fossa $^{[9,25-27]}$.

Because of these drawbacks, surgeons have come to develop several modifications such as using one point fixation of the ZM buttress through a gingivobuccal incision has advantages in that it does not leave an external scar $^{[28,29]}$. However, one-point fixation cannot be used in high energy ZC fracture. Another researchers developed ' $\mathrm{Y}$ ' modification of the transconjunctival approach for high energy ZC fractures to avoid second incision in area of FZ suture but this modification had certain limitations, such as increased operating times and a prolonged duration of swelling in upper lid, resulting in a "hooded" appearance for a period of time ${ }^{[30]}$.

Accordingly, this study was designed as atrial to evaluate clinical and radiographic out-comes of modified two point fixation at ZM buttress and infraorbital rim (IO) versus standard three point fixation in moderate energy OZC fractures.

\section{PATIENTS AND METHODS}

This randomized controlled trial carried out on a total number of thirty two patients. All patients enrolled were suffering from unilateral moderate energy OZC fractures. They indicated for open reduction, fixed according to the random assignment before the operation with either modified two point fixation or standard three point fixation. The study conducted at the Department of Oral and Maxillofacial Surgery, Faculty of Dentistry, Al-Azhar University - Assuit branch, in association with Department of Oral and Maxillofacial Surgery, Faculty of Dentistry, Zagazig University, Egypt over 2 years (from March 2018 to March 2020). Patients signed informed consent after discussing all information about the surgery. The study was approved by the Al-Azhar University ethical committee and done following the Helsinki declaration of human re-search conduct. The observer were not blinded at time of patient examinations and radiographic evaluation. The patients were not blinded because they were informed aim of study.

\section{Grouping:}

All patients were treated by ORIF and some cases needed orbital floor reconstruction . Patients were divided randomly into two equal groups according to fixation technique using the online software (https://www. randomizer.org):

\section{Group I (control group):}

It consist of 16 patients who had OZC fractures that were fixed by standard three point (ZM buttress, IO and ZF areas) fixation technique.

\section{Group II (study group):}

It consist of 16 patients who had OZC fractures that were fixed by modified two point (ZM buttress, IO) fixation technique.

\section{Inclusion criteria:}

\section{Exclusion criteria:}

Exclusion criteria were any other fracture of facial region, zygomatic fractures that can be treated by closed reduction such as isolated zygomatic arch fracture, patients younger than 20 years of age or older than 50 years, patients with incomplete follow-up records and patients with pre-existing deformities, pathology and/or previous $\mathrm{ZMC}$ fractures.

\section{Preoperative phase:}

Demographic information (personal history, history of trauma) and the medical history of each patient were documented. Preoperative extraoral and intraoral clinical examination and radiographic examination included CT scans in three planes with 3D reconstruction were done for all patients (Figures 1a, 2a, 3a, b and 4a, b). All routine laboratory investigations were done for all patients.

\section{Operative Phase:}

The operation was performed under general anesthesia with oroendotracheal intubation. The oral cavity was first scrubbed with povidone iodine, then all around extraoral surgical site followed by draping with sterile towels, exposing only the area of surgery. 


\section{Reduction:}

Intraoral Keen's approach was used for reducing the fractures. It was done through a small incision of approximately $1 \mathrm{~cm}$ made in the mucobuccal fold just beneath the zygomatic buttress of the maxilla. Dingman elevator was passed upwards behind the fractured bone maintaining close contact with the bone in order to avoid entering the fat pad in the temporal area. Reduction was achieved by elevating the bone upward and outward direction.

\section{Fixation:}

In patients of group II modified 2 point fixation technique was performed through the inferior orbital rim was approached using a subciliary incision and The zygomatico maxillary buttress was exposed using intraoral buccogingival incision (Keen's approach). In patients of group I with 3 point fixation, additional exposure of the frontozygomatic suture was accomplished using lateral eyebrow incision.

The fixation method sued was titanium 6 or 4 holed $1.5 \mathrm{~mm}$ miniplates at frontozygomatic suture and $0.9 \mathrm{~mm}$ microplates were used to fix the infraorbital margin while zygomatico maxillary buttress region was fixed with a four holed L-type miniplates $(1.5 \mathrm{~mm}$ thickness, $4.5 \mathrm{~mm}$ width, $22 \times 10 \mathrm{~mm}$ ) (Stryker Leibinger Gmbh and Co. $\mathrm{kG}$, Germany). The screws which used for fixation were of 4.0 and $5.0 \mathrm{~mm}$ length.

Sequence of point fixation was as following: in group I, fixation was done at frontozygomatic suture and zygomatico maxillary buttress region followed by infraorbital rim fracture (Figures $1 \mathrm{~b}, \mathrm{c}, \mathrm{d}$ and e). While in group II, fixation was done at infraorbital rim firstly to assure proper ana-tomical alignment of ZS suture followed by zygomatico maxillary buttress (Figures 2b, c, d and e).
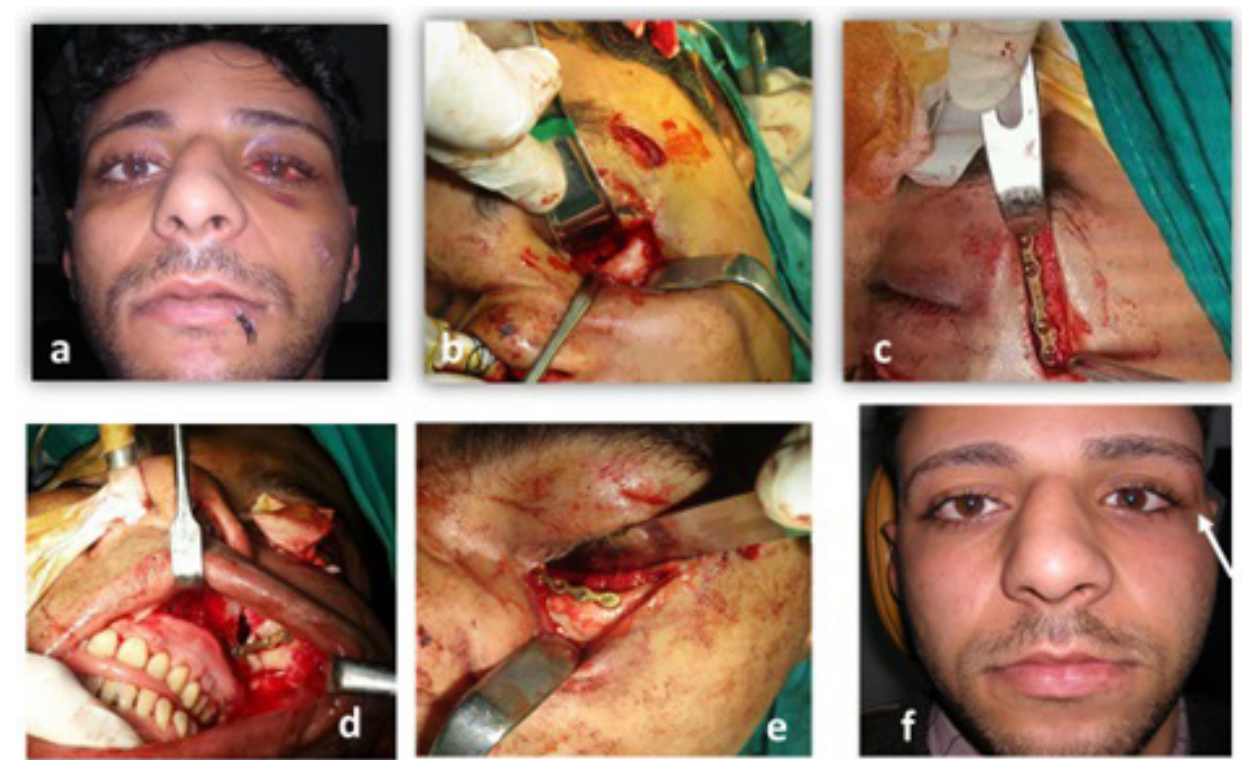

Figure 1: (a) Pre-operative clinical photograph of patient of group I showing left infra-orbital edema and obvious facial asymmetry (b) Subciliary and lateral eye brow approaches (c) Reduction and fixation of frontozygomatic suture by titanium miniplate (d) Reduction and fixation of zygomatico maxillary buttress by titanium miniplate (e) Reduction and fixation of infraorbital rim by titanium miniplate (f) Post-operative clinical photograph at two months showing persistent skin scar at frontozygomatic suture.
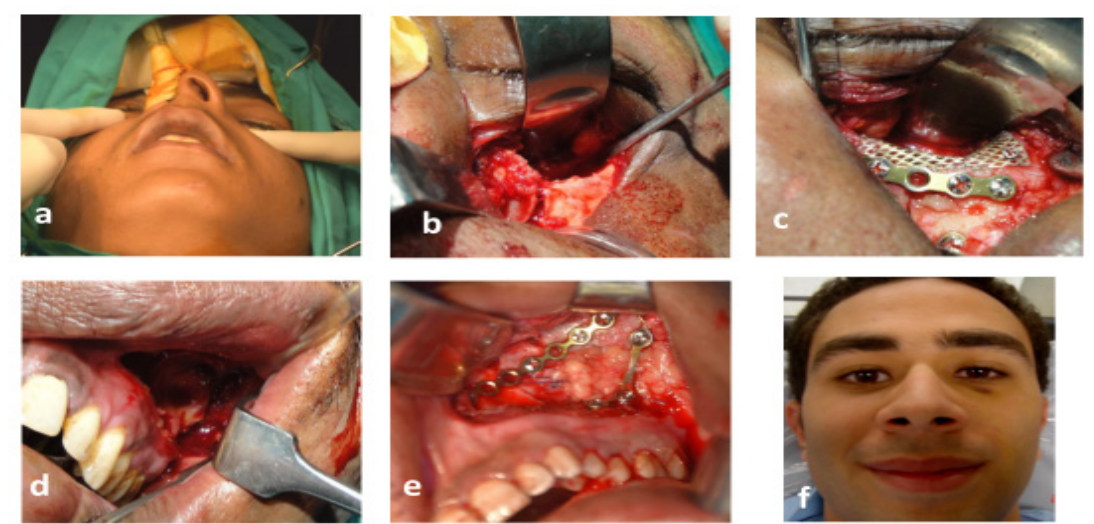

Figure 2: (a) Pre-operative clinical photograph of patient from group II showing obvious facial asymmetry (b) Left inferior orbital rim and orbital floor fractures visualized through an subciliary incision (c) Reduction and fixation of left inferior orbital rim fracture with titanium miniplate and screws and orbital floor reconstruction with titanium mesh (d) Dislocated fracture at the left zygomaticomaxillary buttress and a defect in the anterior wall of the maxillary sinus (e) Reduction and fixation of zygomatico-maxillary buttress with titanium miniplates (f) Post-operative clinical photograph at 6 months. 


\section{Orbital floor reconstruction:}

In most cases, OZC fracture caused a linear orbital floor defect of only a small area that did not need to be closed. The reconstruction of orbital floor was performed with titanium mesh if there is prolapse of adipose tissue to the maxillary sinus after reduction hence an orbital mesh was placed through subciliary incision and adapted to orbital floor then fixed to the inferior orbital rim. After rigidity of the fixation was confirmed, the wound was copiously irrigated. Hemostasis was achieved and watertight closure of soft tissue wound was done in a layer by layer manner.

\section{Postoperative Phase care:}

Analgesics, anti inflammatory drugs, antibiotics, and antiseptic mouthwash were prescribed for 7 days postoperatively. The maintenance of a soft diet and good oral hygiene was recommended for 2 weeks after surgery.

Patients were followed up, on $3^{\text {rd }}$ day followed by $7^{\text {th }}$ day for suture removal, later followed up on $2^{\text {nd }}$ week and a monthly follow up thereafter. Outcome of open reduction of Zygoma was assessed after completion of 6 months.

\section{Postoperative evaluation:}

Postoperative clinical, patient satisfaction and radiographic assessments were done after six months follow up.

\section{Clinical evaluation:}

Post-operative clinical evaluation was conducted through visual inspection of the zygomatic projection from behind the patient and from in front of the patient to check for the eye globe position, obvious facial asymmetry and ocular movement. Also, palpation of the zygomatic complex articulations to inspect for any palpable steps and palpation of plate prominence over lateral orbital rim and infraorbital rim. Intra-oral inspection was also carried to assess the occlusion and postoperative trismus. Patient satisfaction was assessed by a gradient scale from 1 to 10,1 being totally unsatisfied and 10 being completely satisfied to the overall outcome after the surgical in-tervention.

\section{Radiographic evaluation:}

CT images were acquired on a SOMATOM Definition Flash scanner (Siemens AG, Muenchen, Germany) following trauma protocols for CT scanning $(512$ x 512 matrix, $150 \mathrm{~mA}, 140 \mathrm{kV}$, scan time $=2.0$ seconds). The scans were performed at consecutive $1.0-\mathrm{mm}$ intervals extending from the superior aspect of the orbit to inferior border of the mandible axially and from anterior nasal spine to posterior aspect of the foramen magnum coronally. Full CT studies, both preand postoperative were transferred to Syngo Acquisition Work Place (Siemens AG, Muenchen, Germany) and displayed in bone algorithms for measurements using syngo. via software (provided by Siemens AG, Germany). Where, each patient's Digital Imaging and Communication
Medicine (DICOM) data was transferred to the workstation for a series of measurements as described by Furst et al. ${ }^{[31]}$. Measurements were obtained pre and postoperatively after sex month from surgery to assess the quality of reduction to the nearest $0.1 \mathrm{~mm}$ and bony gaps at fracture lines exceeding $2 \mathrm{~mm}$ being considered suboptimal reduction.

\section{Statistical analysis:}

The study variables data were collected and coded using the statistical package of social sciences (SPSS, version 24, Chicago, Illinois, USA) program for statistical analysis. Descriptive and inferential analyses were performed using t-test and chi-square test for association. $P$-value was set at or below 0.05 to define significance.

\section{RESULTS}

\section{Demographic data:}

Thirty two patients (22 male and 10 female) suffered from unilateral moderate energy OZC fractures were included in the present study and their age ranged between 21 and 49 years. The mean age of patients in group I was $30.11 \pm 10.94$ years, and $35.15 \pm 13.91$ years in group II. Males predominated with a percentage of $68 \%$ of the cases. The result of etiology showed that overall $17(53.1 \%)$ patients had fracture due to RTA, $8(25.4 \%)$ due to fall, $5(15.6 \%)$ due to assault and $2(6.25 \%)$ due to sports. In patients of group I $51.5 \%$ had fracture due to RTA, $32.0 \%$ due to fall, $8.9 \%$ due to assault, and $7.6 \%$ due to sports. In patients treated with three point fixation $52.6 \%$ had fracture due to RTA, $30.9 \%$ due to fall, $10.9 \%$ due to assault, and $5.7 \%$ due to sports.

\section{Clinical results:}

Intraoperative, modified two point fixation technique was superior in time-saving and feasibility of its manipulation with statistically significant difference $(p<0.01)$ than three point fixation technique but average duration of hospital stay was similar without any significant difference $(p>0.05)$ (Table 1). Postoperatively, all fractures healed uneventfully without complica-tions as infection or plate loosening. The hypertrophic scar was seen as late manifestation of wound healing in two cases of group I, where plastic revision was done, and silicone creams or patches were initiated.

\section{Postoperative complications and patients satisfaction score:}

Nine parameters were examined clinically at sex months (Figure 3). Palpable ZMC articula-tions occurred in 4 patients $(25 \%)$ of group I and 5 patients $(31.2 \%)$ in group II. Flattening of ma-lar occurred in 2 patients $(12.5 \%)$ of group I and 3 patient $(18.7 \%)$ in group II. Plate prominence over infraorbital rim occurred at the same number of patients (2 patients $(12.5 \%)$ ) in both groups. While, Plate prominence over lateral orbital rim was showed in 5 patients $(31.2 \%)$ of group I only. Facial asymmetry was observed in $3(18.7 \%)$ patients of group I 
and $4(25 \%)$ patients of group II and uneven globe position appearance was observed in $2(12.5 \%)$ patients of group I and $3(18.7 \%)$ patients in group II . Post-operative abnormal ocular movement was observed in $2(12.5 \%)$ patients of group I and one $(6.3 \%)$ patient in group II. A total of one patient $(6.3 \%)$ of group I and two $(12.5 \%)$ patients of group II experienced post-operative malocclusion. No one of patients in both groups complained from trismus at postoperative two months. There was high statistically significant difference $(p<0.01)$ between percent of patients complained from postoperative complications in both groups. Where, it was higher in group I (43\%) than group II $(25.5 \%)$. Accordingly, patient satisfaction score values of group II were higher than group I values with high statistically significant difference between both group $(p<0.01)($ Table 1$)$.

\section{Rate of postoperative complications in groups}

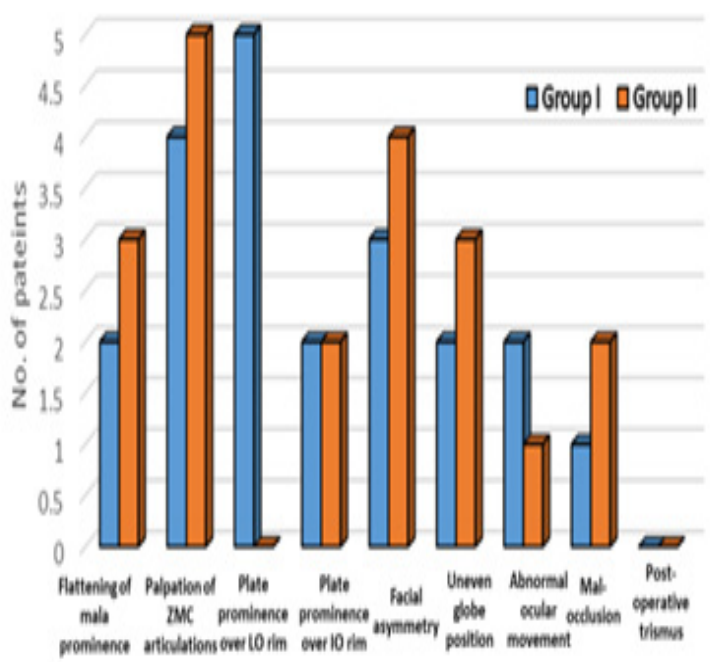

Figure 3: Barchart showing comprasion between groups regarding postoperative complications.
Table 1: Comparsion between groups at aspects of operation time, hospital stay, number of pateints with postoperative complications, and patient satisfaction score:

\begin{tabular}{llcl}
\hline Case & Group I & Group II & $P$-value \\
\hline $\begin{array}{l}\text { Operation time } \\
\text { (ORIF only), minute }\end{array}$ & $145.06 \pm 35.50$ & $106.25 \pm 29.52$ & $0.015^{* *}$ \\
$\begin{array}{l}\text { Operation time } \\
\text { (ORIF and orbital } \\
\text { reconstruction), } \\
\text { minute }\end{array}$ & $215 \pm 20.51$ & $175 \pm 19.72$ & $0.001^{* *}$ \\
$\begin{array}{l}\text { Hospital stay, day } \\
\text { Number of patients } \\
\text { with postoperative } \\
\text { complications }\end{array}$ & $3.45 \pm 2.00$ & $4.25 \pm 1.29$ & 0.418 \\
$\begin{array}{l}\text { Patient satisfaction } \\
\text { score }\end{array}$ & $4.40 \pm 2.59$ & $7.250 \pm 1.832$ & \\
\hline
\end{tabular}

**: High statistically significant when $p \leq 0.01$.

\section{Postoperative Radiographic measurements:}

According to postoperative radiographic findings of our study, all radiographic measurements revealed statistically significant differences than preoperative measurements in both groups. Postoperatively, there was statistically significant differences between measurements of unaffected side and affected side in both groups without any statistically significant differences between both groups in values of mean difference between affected and unaffected sides at all measurements $(p>0.05)$ (Figure 4 and Table 2).

Regarding quality of bone reduction, a total of 23 $(71.8 \%)$ patients were acceptably reduced and $9(28.1 \%)$ patients were considered sub optimally reduced. Within group I, 12 patients revealed acceptable reduction, with a mean difference $(1.63 \pm 0.27)$, with only 4 patients showing suboptimal reduction with a mean difference of $(1.42 \pm 0.35)$. Within group II, 11 patients revealed acceptable reduction, with a mean difference $(1.54 \pm 0.73)$, with only 5 patients showing suboptimal reduction with a mean difference of $(1.62 \pm 0.21)$. 

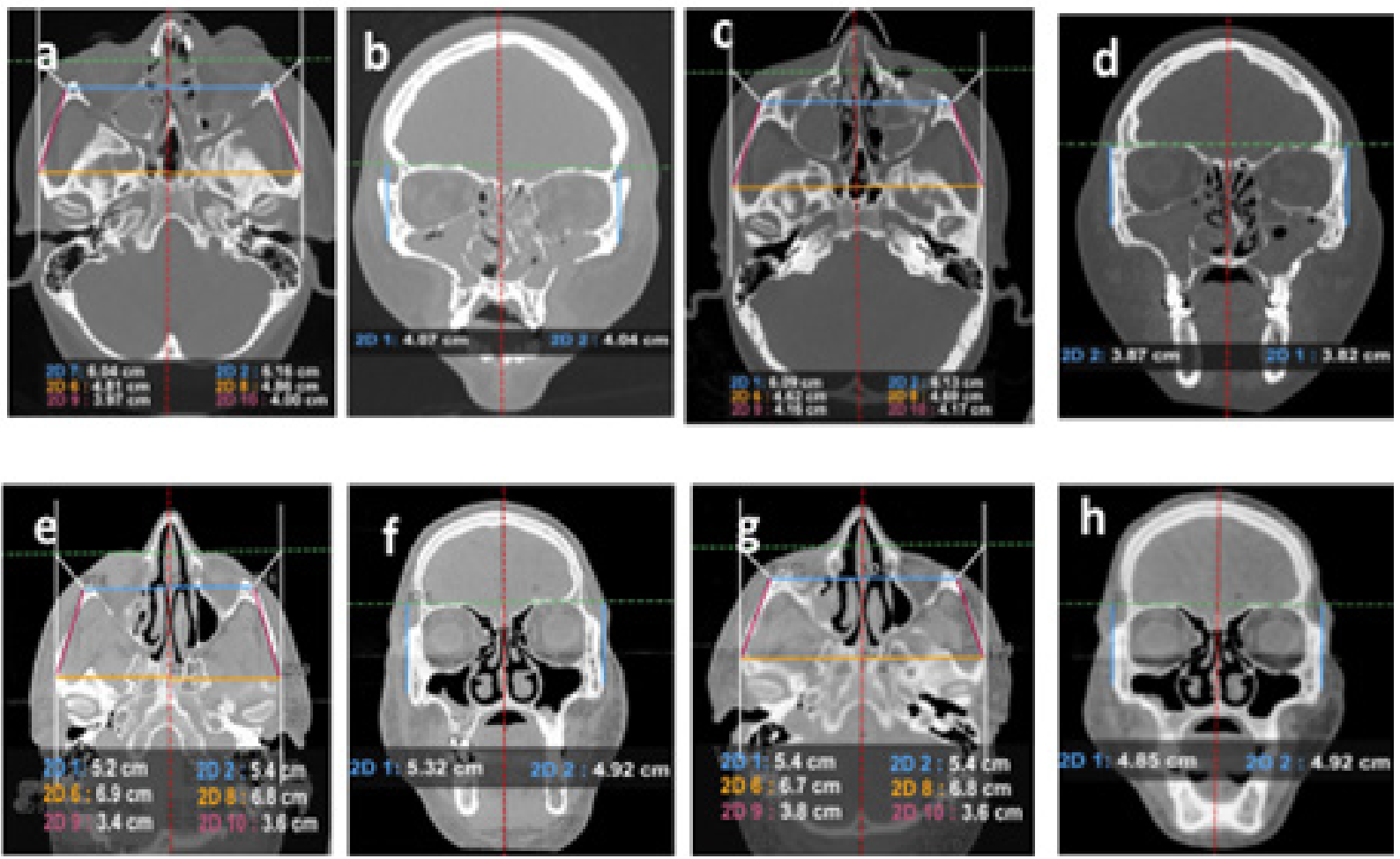

Figure 4: (a, b) Pre-operative axial and coronal cuts of CT in group I scan showing different measurements. (c, d) Post-operative axial and coronal cuts of $\mathrm{CT}$ in group I scan showing different measurements (e, f) Pre-operative axial and coronal cuts of $\mathrm{CT}$ in group II scan showing different measurements. $(\mathrm{g}, \mathrm{h})$ Post-operative axial and coronal cuts of $\mathrm{CT}$ in group II scan showing different measurements.

Table 2: Pre and postoperative radiographic measurements at affected, and unaffected side and comparison between values of mean difference between two sides in groups:

\begin{tabular}{|c|c|c|c|c|c|c|c|c|c|}
\hline \multirow{3}{*}{$\begin{array}{l}\text { Measurements } \\
\qquad(\mathrm{cm})\end{array}$} & \multicolumn{4}{|c|}{ Group I } & \multicolumn{4}{|c|}{ Group II } & \multirow{3}{*}{$P$ value } \\
\hline & \multirow{2}{*}{$\begin{array}{l}\text { Unaffected } \\
\text { side }\end{array}$} & \multicolumn{2}{|c|}{ Affected side } & \multirow{2}{*}{$\begin{array}{c}\text { Mean } \\
\text { difference } \\
\text { between } \\
\text { two sides }\end{array}$} & \multirow{2}{*}{$\begin{array}{l}\text { Unaffected } \\
\text { side }\end{array}$} & \multicolumn{2}{|l|}{$\begin{array}{l}\text { Affected } \\
\text { side }\end{array}$} & \multirow{2}{*}{$\begin{array}{c}\text { Mean } \\
\text { difference } \\
\text { between } \\
\text { two sides }\end{array}$} & \\
\hline & & Pre & Post & & & Pre & Post & & \\
\hline $\begin{array}{l}\text { Posterior } \\
\text { zygomatic } \\
\text { complex width }\end{array}$ & $6.04 \pm 1.02$ & $6.16 \pm 1.72$ & $6.13 \pm 0.61$ & $0.09 \pm 0.41$ & $6.81 \pm 1.14$ & $6.93 \pm 1.91$ & $6.74 \pm 0.23$ & $0.07 \pm 0.29$ & 0.993 \\
\hline $\begin{array}{l}\text { Anterior } \\
\text { zygomatic } \\
\text { complex width }\end{array}$ & $4.81 \pm 0.91$ & $4.86 \pm 1.63$ & $4.69 \pm 0.24$ & $0.11 \pm 0.52$ & $5.46 \pm 0.91$ & $5.20 \pm 0.72$ & $5.40 \pm 1.02$ & $0.06 \pm 0.16$ & 0.098 \\
\hline $\begin{array}{l}\text { Zygomatic } \\
\text { complex } \\
\text { pro-jection }\end{array}$ & $3.97 \pm 0.83$ & $4.00 \pm 1.02$ & $4.17 \pm 0.31$ & $1.80 \pm 0.72$ & $3.62 \pm 0.74$ & $3.45 \pm 2.01$ & $3.81 \pm 0.94$ & $0.36 \pm 0.20$ & 0.515 \\
\hline $\begin{array}{l}\text { Zygomatic } \\
\text { complex } \\
\text { height }\end{array}$ & $3.87 \pm 0.13$ & $4.07 \pm 2.14$ & $3.82 \pm 0.15$ & $0.05 \pm 0.02$ & $4.92 \pm 0.87$ & $5.32 \pm 1.75$ & $4.85 \pm 0.95$ & $0.07 \pm 0.08$ & 0.188 \\
\hline
\end{tabular}


Comparing cases of both groups regarding the postoperative reduction, Chi square test revealed a nonsignificant difference between acceptable reduction cases in both groups. Moreover, Unpaired t test revealed a nonsignificant difference between both groups related to mean difference values between measurements of affected and unaffected sides (Table 3).
Demographic results of present study showed that the mean age of patients was 35 (group I, mean 30.11 and Group II mean age 35.15) years. Third decade constituted the major group in this study, which is the same as previous studies by Tanaka ${ }^{[33]}$, Anwar et al. ${ }^{[34]}$, Fasola $\mathrm{AO}^{[35]}$. This is explained by that the adult is more vulnerable due to

Table 3: Comparison between groups regarding quality of reduction and mean difference ( $\mathrm{mm}$ ) between affected and unaffected sides:

\begin{tabular}{|c|c|c|c|c|c|c|}
\hline & \multicolumn{2}{|c|}{ Group I } & \multicolumn{2}{|c|}{ Group II } & \multirow{2}{*}{ Statistical test } & \multirow{2}{*}{$\begin{array}{c}P \\
\text { value }\end{array}$} \\
\hline & Acceptable reduction & Suboptimal reduction & Acceptable reduction & Suboptimal reduction & & \\
\hline No. of cases & 12 & 4 & 11 & 5 & \multirow{2}{*}{$\begin{array}{l}\text { Chi square } \\
=19.6\end{array}$} & \multirow[b]{2}{*}{0.193} \\
\hline Percent of cases & $75 \%$ & $25 \%$ & $69.5 \%$ & $31.2 \%$ & & \\
\hline $\begin{array}{l}\text { Mean difference }(\mathrm{mm}) \\
\text { between affected and } \\
\text { unaffected sides }\end{array}$ & $1.63 \pm 0.27$ & $1.42 \pm 0.35$ & $1.54 \pm 0.73$ & $1.62 \pm 0.21$ & $\begin{array}{c}\mathrm{t} \text { test: } \\
\mathrm{t}=5.122\end{array}$ & 2.153 \\
\hline
\end{tabular}

\section{DISCUSSION}

The OZC fracture is tripod or tetrapod zygoma fracture involving orbital walls with disruption at its four articulating processes. The zygoma or malar complex forms central support of cheek, shears in formation of orbital skeleton and act as major buttress of mid face ${ }^{[3,9]}$. There-fore. The zygoma plays an important role in facial contour and orbital cavity integrity for both cosmetic and functional reasons ${ }^{[10]}$.

Functional impairment after ORIF for OZC fractures, such as restricted mouth opening, sensory deficits, enophthalmos, diplopia or facial asymmetry can arise from inadequate reduction or secondary displacement following initial reduction as a result of masticatory forces ${ }^{[5-8,32]}$. Therefore, the goals of treatment of zygomatic fractures are accurate reduction and fixation to restore and maintain original facial skeletal configuration ${ }^{[11-13]}$. However, there is still a contro-versy about number of point fixation $^{[22-25]}$.

Several studies ${ }^{[20}$ - 23] preferred three-point fixation techniques at ZF, IO and ZM articulation to overcome physiological stresses and maintain stability at fracture sites in a OZC fracture. These sites have been approached through lateral brow, subciliary or transconjunctival, and intraoral incisions, respectively. Although, another studies ${ }^{[24-26,28]}$ preferred two point fixation, where it is also sufficient to maintain stability and show good results in selected cases.

One of patients concerns during OZC fracture management is restoration of their aesthetic appearance after surgery without any skin scars or facial asymmetry. Therefore, the present study was designed to compare modified two point fixation excluding ZF point fixation with standard three point fixation for management of OZC fracture to avoid sequelae of lateral brow incision and ORIF of the ZF suture such as noticeable scar, palpation of plates and ectropion. dominant outdoor activities at that stage of life as reported by Adekeye ${ }^{[36]}$.

Regards to sex prediction, our study revealed that majority of our patients presenting with OZC fractures were males where Males predominated with a percentage of $68 \%$ of the cases. This was in the same side with Rana et al..$^{[22]}$ explanation. Who explained that females are more confined to indoor activities whereas males are more exposed to external environment during commuting as well as during their jobs.

Tanaka et al. ${ }^{[33]}$ and Anwar ${ }^{[34]}$ concluded that the most common reasons for zygomatic complex fractures include road traffic accidents, followed by physical assaults, fall and sports injuries. This matched with our results where overall $17(53.1 \%)$ patients had fracture due to RTA, $8(25.4 \%)$ due to fall, $5(15.6 \%)$ due to assault and $2(6.25 \%)$ due to sports.

Manson et al. ${ }^{[37]}$ classified OZC into low- low energy fractures, moderate energy fractures and high energy fractures. Authors ${ }^{[38]}$ stated that low energy fractures occurs in $(18 \%)$ of all OZC fractures and characterized by at least one incomplete fracture, most often, that of the frontozygomatic suture and usually no surgical management is required. Moderate energy fractures comprise $(77 \%)$ of the OZC fractures and characterized by mild to moderate dislocation with respect to all the sutures and by disintegration of fracture edges. Therefore, they usually need ORIF for management high energy OZC fractures are usually components of the Le Fort or panfacial fractures. They can rarely be observed as an isolated entity (5\%). According this clas-sification moderate energy fractures were indicated in the present study because they most commonly occur.

The present study demonstrated that there was high statistically significant difference between groups in aspects of time saving and feasibility of technique with superiority for modified two point fixation technique in cases with or 
without orbital reconstruction $(P$ value: 0.001 and 0.015 respectively), but average duration of hospital stay period was similar ( $P$ values: 0.418$)$. This was in agreement with results of Hyeok Kim et al. ${ }^{[39]}$ study.

Regarding number of patients complained postoperative complications and patients satisfaction score, there was high statistically significant difference between groups ( $P$ values: $0.003,0.0016$ respectively). Postoperative complications was comparable between groups with out any statistical significant difference except complain of plate prominence over lateral orbital rim was the most prominent in group I than group II. Where, bone plate at lateral orbital rim wasn't done in modified two point fixation technique. This was in acceptance with Jolly et al. ${ }^{[26]}$ and Hyeok Kim et al. ${ }^{[39]}$ studies. In the other hand, Zaman et $a l .{ }^{[23]}$ concluded that three point fixation is superior to two point fixations in terms of achieving optimal malar height and two point fixation was primarily used to reduce the scar mark of incision only.

Radiographic results of our study revealed that all postoperative radiographic measurements at affected revealed statistically significant differences than preoperative measurements of the same side in both groups. While, there was a nonsignificant difference between acceptable reduction cases in both groups. Moreover, Unpaired t test revealed a nonsignificant difference between both groups related to mean difference values between measurements of affected and unaffected sides. This showed that fixation techniques that tried in this study were similar in quality of reduction aspect. This was in the same side with Hyeok Kim et al.$^{[39]}$ conclusions although their study was retrospective study with small sample of participating patients. They pre-ferred two point fixation over three-point as it did not achieve any extra benefits from these ap-proaches in relation to reduction and stabilization points of view. Therefore two point fixation had equal level of stability with three point fixation with overcoming noticeable scar and plate prominence over lateral orbital rim.

Several studies ${ }^{[24-26,39-40]}$ preferred two point fixation over three point and four point fixation as they did not achieve any extra benefits from these approaches in relation to reduction and stabilization points of view. They concluded that three or four point fixation of zygoma is not necessary except for comminuted fractures. Although all these literature support the idea of two point fixation over three point, there are few clinical studies which investigated that modified two point fixation technique is better than standard three point fixation technique in the management of OZC fractures. These studies do not favor the results of our study; however; these studies differ from our study regarding site of fixation as well as type of study (controlled or no). Our study characterized than them by it evaluated patients satisfaction score and radiographic measurements to assess quality of reduction and restoration of orbital dimensions after ORIF.
Parashar et al. ${ }^{[32]}$ evaluated efficacy of another type of two point fixation which differs from our present study in one major aspect as two-point fixation was done over frontozygomatic and inferior orbital region. As ZM buttress which was left untreated in this study might result in post-surgical displacement of Zygoma secondary to the action of masseter muscle.

Our study has some limitations including a short term follow-up period, relatively few patients number and cannot evaluate orbital volume after ORIF by advanced 3-D radiographic software. Despite these limitations, modified two point fixation technique can provide sufficient bony stability without external scars. We suggest that our surgical technique offers an alternative treatment for moderate OZC fractures.

\section{CONCLUSION}

This clinical study suggests that modified two point fixation of OZC fracture without $\mathrm{FZ}$ suture fixation provides reliable, satisfactory and safe clinical results in patients with OZC fractures. This technique presents the same surgical outcomes of traditional three point fixation but it has advantages of reduction of operation time ,and postoperative complications such as noticeable scar and a palpable plate via the skin at lateral eye brow.

\section{CONFLICT OF INTEREST}

The authors declare no conflict of interest.

\section{REFERENCES}

1. Farber SJ, Nguyen DC, Skolnick GB, et al: Current management of zygomaticomaxillary complex fractures: A multidisciplinary survey and literature review. Craniomaxillofac Trauma Reconstr 2016; 9: 313 - 20.

2. Ferreira, P., Marques, M., Pinho, C., et al. Midfacial fractures in children and adolescents: A review of 492 cases. The British Journal of Oral and Maxillofacial Surgery 2004; 42, $501-5$.

3. Yeşiloğlu N, Şirinoğlu H, Sarici M, Temiz G, Filinte G. A new option for the reconstruction of orbital floor defects. Ann Plast Surg. 2015; 75: $401-6$.

4. Czerwinski, M., Martin, M., and Lee, C. Quantitative topographical evaluation of the orbitozy-gomatic complex. Plastic and Reconstructive Surgery 2005; 115: $1858-62$.

5. Raschke $\mathrm{G}$, Rieger $\mathrm{U}$, Bader $\mathrm{R}$, et al. The zygomaticomaxillary complex fracture - an anthro-pometric appraisal of surgical outcomes. J Cranio Maxillo Fac Surg. 2013; 41: 331 - 7. 
6. Gander T, Essig H, Metzler P, et al. Patient specific implants (PSI) in reconstruction of orbital floor and wall fractures. J Cranio-Maxillo-Fac Surg. 2015; 43: $126-130$.

7. Ebrahimi A, Motamedi M, Rasouli H, and Naghdi N. Enophthalmos and Orbital Volume Changes in Zygomaticomaxillary Complex Fractures: Is There a Correlation Between Them? J Oral Maxillofac Surg 2019; 77: 134 - 43.

8. Tong, L., Bauer, R. J. and Buchman, S. R.. Acurrent 10-year retrospective survey of 199 surgically treated orbital floor fractures in a nonurban tertiary care center. Plastic and Reconstructive Surgery 2001; 108 (3): $612-21$.

9. Kelley, P., Hopper, R. and Gruss, J.. Evaluation and treatment of zygomatic fractures. Plastic and Reconstructive Surgery 2007, 120 (7): 5 - 15.

10. Ellis $3^{\text {rd }}$ E. Orbital trauma. Oral Maxillofac Surg Clin. 2012; 24: $629-48$.

11. Avashia Y, Sastry A, Fan K, Mir H, Thaller S. Materials used for reconstruction after orbital floor fracture. J Craniofac Surg. 2012; 23: $49-55$.

12. Oh $\mathrm{T}$, Jeong $\mathrm{W}$, Chang $\mathrm{T}$, Koh $\mathrm{K}$, Choi J. Customized orbital wall reconstruction using three dimensionally printed rapid prototype model in patients with orbital wall fracture. J Craniofac Surg. 2016; 27: $2020-4$.

13. Pedemonte C, Sáez F, Vargas I, González L, Canales M, Salazar K. Can customizedm implants correct enophthalmos and delayed diplopia in post traumatic orbital deformities? A volumetric analysis. Int $\mathrm{J}$ Oral Maxillofac Surg. 2016; 45: $1086-94$.

14. Stanley, R. B., Sires, B. S., Funk, G. F. and Nerad, J. A.. Management of displaced lateral orbital wall fractures associated with visual and ocular motility disturbances. Plastic and Reconstructive Surgery 1998; 102 (4): $972-9$.

15. al-Qurainy, I. A., Stassen, L. F., Dutton, G. N., et $a l$. .Diplopia following midfacial fractures. The British Journal of Oral and Maxillofacial Surgery 1991; 29 (5): $302-7$.

16. M. Eski, I. Sahin, M. Deveci, M. Turegun, S. Isik, and M. Sengezer, "A retrospective analysis of 101 zygomaticoorbital fractures," Journal of Craniofacial Surgery 2006; 17 (6): 1059 - 64.
17. Meslemani D , and Kellman RM, "Zygomaticomaxillary complex fractures," Archives of Fa-cial Plastic Surgery 2012; 14 (1): $62-6$.

18. Hwang K, Kim DH. Analysis of zygomatic fractures. J Craniofac Surg. 2011; 22 (4): $1416-21$.

19. D. Rohner, A. Tay, C. S. Meng, D. W. Hutmacher, and B. Hammer, "the sphenozygomatic suture as a key site for osteosynthesis of the orbitozygomatic complex in panfacial fractures: a biomechanical study in human cadavers based on clinical practice," Plastic and Reconstructive Surgery 2002; 110 (6): 1463 - 71 .

20. Pearl RM. Treatment of enophthalmos. Clin Plast Surg. 1992; 19: 99 - 111.

21. O'Hara DE, Delvecchio DA, Bartlett SP. The role of microfixation in malar fractures: a quantitative biophysical study. Plast Reconstr Surg. 1996; 97: 345 - 53.

22. Rana et al.: Surgical treatment of zygomatic bone fracture using two points fixation versus three point fixation-a randomised prospective clinical trial. Trials 2012; 13 (36): 1 - 10.

23. Zaman G, Khan MA, Hyder MZ, Hassan TU, Zafar A, Ashraf W. et al.. Three point fixation is superior to two point fixation technique for zygomatic complex fracture. Int $\mathrm{J}$ Clin Trials 2019; 6 (4): 61 - 6 .

24. Abdullah K, Shahzad M, Bhangwar AW, Hassan SG, Panjabi SK. Isolated Zygomatic bone fracture: assessment of outcome by two point fixation. Professional Med J 2020; 27 (2): 246 - 50.

25. T. Jo and J. Kim, "An anthropometric and three dimensional computed tomographic evaluation of two point fixation of zygomatic complex fractures," Archives of Plastic Surgery 2014; 41 (5): 493 - 9.

26. Jolly S, Ahmad F, Gupta P, Singh D and Sooch S. zygomatico maxillary complex fracture: two point vs. three point fixation. WJPMR 2019, 5 (7), 164 - 9.

27. S. T. Kim, D. H. Go, J. H. Jung, H. E. Cha, J. H. Woo, and I. G. Kang, "Comparison of 1 point fixation with 2 point fixation in treating tripod 
fractures of the zygoma," J Oral Maxillofac Surg 2011; 69 (11): $2848-52$.

28. Kim SY, Nam SM, Park ES and Kim YB. Evaluation of one-point fixation for zygomati comaxillary complex fractures using a three dimensional photogrammetric analysis. Journal of Otolaryngology - Head and Neck Surgery 2019; 48: 36 - 44 .

29. Fujioka M, Yamanoto $T$, Miyazato $O$, Nishimura G. Stability of one plate fixation for zygomatic bone fracture. Plast Reconstr Surg. 2002; 109: 817 - 8 .

30. Rajkumar K, Mukhopadhyay P, Sinha R, Bandyopadhyay TK.. Modification of the trans-conjunctival approach for management of zygomatic complex fractures: a prospective analysis. J Maxillofac Oral Surg 2016; 15: 45 - 51.

31. Ian Furst, Peter Austin, Michael Pharoh, James Mahony. The use of computed tomography to define zygomatic complex position. J Oral Maxillofac Surg 2001; 59: 647 - 654.

32. Prashar A, Sharma RK, Makkar S. Rigid internal fixation of zygoma fractures: A comparison of two point and three-point fixation. Indian J Plast Surg, 2007; 40: 1 - 7 .

33. Tanaka ON, Tomitsuka K, Shionoya K, Andou H, Kiimijima Y: Etiology of maxillofacial fractures. Br J Oral Maxillofac Surg 1994, 32: 19 - 23.
34. Anwar BB: Etiology and incidence of maxillofacial fractures in north of Jordan. Oral Surg Oral Med Oral Pathol 1998, 86: 31 - 5 .

35. Fasola AO, Obiechina AE, Arotiba JT: Zygomatic complex fractures at the University College Hospital, Ibadan, Nigeria. East Afr Med J 2002, 79: 11 - 3 .

36. Adekeye EO: Fracture of zygomatic complex in Nigerian patient. J Oral Surg 1980, 38: 596 - 599.

37. Manson, P. N., Markowitz, B., Mirvis, S et al.. Toward CT-based facial fracture treatment. Plastic and Reconstructive Surgery, 1990; 85 (2): $202-12$.

38. V. P. Nikolaenko, and Y. S. Astakhov (Eds.) (2015). Orbital fractures: Aphysician's manual. Heidelberg: Springer. Chapter of Zygomaticoorbital Fractures, Pp 272 - 294.

39. Hyeok Kim J, Sol Kim Y, Young Oh D, Joon Jun

Y, Won Rhie J,and Moon S. Efficacy of Altered Two Point Fixation in Zygomaticomaxillary Complex Fracture. BioMed Research International. 2020, 3: 1 - 7 .

40. Chattopadhyay PK, Chander, M. Management of Zygomatic Complex Fracture in Armed Forces. Med J Armed Forces India 2009; 65: 128 - 30. 